\title{
Antibacterial and antifungal activities of extracts of Convolvulus leiocalycinus and Haloxylon griffithii of Balochistan, Pakistan
}

\author{
Anum Mengal $^{1}$, Samiullah ${ }^{1 *}$, Naqeebullah Khan ${ }^{1}$, Attiq-Ur-Rehman ${ }^{1}$ \\ and Abdul Baqi ${ }^{1,2}$ \\ 1. Department of Chemistry, University of Balochistan, Quetta 87300-Pakistan \\ 2. Colleges Higher and Technical Education Balochistan, Quetta 87300-Pakistan \\ *Corresponding author's email: sami435889@gmail.com \\ Citation \\ Anum Mengal, Samiullah, Naqeebullah Khan, Attiq-Ur-Rehman and Abdul Baqi. Antibacterial and antifungal \\ activities of extracts of Convolvulus leiocalycinus and Haloxylon griffithii of Balochistan, Pakistan. Pure and \\ Applied Biology. Vol. 8, Issue 4, pp2286-2294. http://dx.doi.org/10.19045/bspab.2019.80175
}

\begin{tabular}{llll}
\hline \hline Received: 20/05/2019 & Revised: 15/07/2019 & Accepted: 24/07/2019 & Online First: 03/08/2019 \\
\hline
\end{tabular}

\section{Abstract}

Different medicinal plants have the potential of antibacterial and antifungal activities. Therefore, this research was executed to assess the antibacterial and antifungal activities of different fractions i.e. water $\left(\mathrm{H}_{2} \mathrm{O}\right)$, chloroform $\left(\mathrm{CHCl}_{3}\right)$, n-hexane $\left(\mathrm{C}_{6} \mathrm{H}_{14}\right)$ and ethyl acetate $\left(\mathrm{C}_{4} \mathrm{H}_{8} \mathrm{O}_{2}\right)$ of Convolvulus leiocalycinus and Haloxylon griffithii by applying Agar well diffusion method. Bacterial strains of four types i.e., 3 gram-negative and 1 gram-positive namely Escherichia coli, Klebsiella pneumonia, Staphylococcus aureus, Pseudomonas aeruginosa and a fungal strain like PBF-1 were used to investigate the antibacterial and antifungal activities in the selected plant extracts. The water, chloroform, ethyl acetate and nhexane fractions of $C$. leiocalycinus exhibited antibacterial activities of 7, 7, 7 and $6 \mathrm{~mm}$ zone of inhibition respectively against $S$. aureus bacteria. Consequently, the same four fractions of $H$. griffithii displayed antibacterial activities against $S$. aureus 8, 8, 9 and zero $\mathrm{mm}$ zone of inhibition respectively. Considering the antifungal activity, the ethyl acetate fraction of $C$. leiocalycinus showed strong inhibition i.e., ++. But in $H$. grifithii, only the n-hexane fraction gave partial inhibition in antifungal activity. These results indicated that the ethyl acetate fraction of $C$. leiocalycinus exhibited strong antifungal activity as compared with the same fraction of $H$. griffithii showing that $C$. leiocalycinus is more potent as compared to $H$. griffithii. This justifies the usage of both plants in traditional medicines in future. It is also suggested that the use of entire extract of both the plants in foods can improve their shelf life.

Keywords: Agar well diffusion; Antibacterial activity; Antifungal activity; fungal strain PBF1 .

\section{Introduction}

Although, immense development in human medication, infective disorders produced by viruses, fungi, parasites and bacteria are yet a major risk to the health of humans. The effects are far more savior on developing nations by reason of the absence in development of widely spread drug resistance [1]. The resistance of drugs over the last 2 decades is in development along with the undesirable side effects. Appearance of some antibiotics [2] has directed to the discoveries of the modern antimicrobial agents in plant extracts with 
the purpose of discovering new chemical structures, converting above drawbacks [3]. World's $80 \%$ of available medicines utilized in developing countries are from medicinal plants [4]. A wide-ranging variety of medicinal plants utilized in the extraction as raw drugs having different medicinal properties. Local communities collect very minimum amounts of the raw drugs and used for local use by local healers, various other drugs are collected in huge scale and merchandised in market, which for many herbal industries are raw material [5]. Clinical microbiologists are very interested in screening of medical medicine for new treatments [6]. The active principle of numerous drugs originate in the plants are secondary metabolites. The antimicrobial activities from extracts of plants are existing in different components, phenolic compounds and aldehydes are also included [7]. Drug resistance preparation against normally used antibiotic in human pathogens needs to find latest antimicrobial substances including plants from other sources [8].

Resistance of bacteria against antibiotics has become an increasingly global concern [9]. Extreme caution doctors believe that bacteria which are resistant towards antibiotic an important or major issue in treating patients [10]. Resistance of bacteria is encouraging to resume in the role of antimicrobial research herbs against resistant strains [11, 12]. A large quantity of medicinal plants has been known as a beneficial resource for natural antimicrobial compounds [13]. Medicinal plant extracts provide sufficiently potential for growth of new agents which is effective against contaminations formerly problematic to treat [14].

A large extent antibiotics utility is the development of microbe resistance and this resistance is spreading around the globe $[15,16]$. The result of the failure of the resulting therapy increases. Another limit for the use of antibiotics is the rising price $[17,18]$. Synthetic organic compounds are more than $99 \%$ but still natural products are more than the third part of all drug sales [19].

The high means of antimicrobial molecules are the availability of medicinal plants. A number of medicinal plants extracts are used to treat many diseases because they have potential protection activity. Some of these bioactive molecules are screened and traded in a market like raw substance for many herbal industries [20]. After observing more side effects of artificial drugs compared to their benefits, experts focused on gaining benefits from medicinal plants [21]. Out of 422127 plant species have been reported worldwide, it is estimated that approximately 35000 to 70000 plant species are used as medicinal plants [22]. Approximately, 80\% population of rural areas in Pakistan depends on traditional medicines [23].

Medicinal plants can provide abundance of antimicrobial agents and has been examined for hundreds of biological activities. Small amounts of crude materials are collected by local people and they use them to cure infections. Raw material is also collected on a large scale and is sent to deliver trade in the market to the herbal industries [5]. Parasites and pathogens will be the biggest hazard to humans. Pathogens are allowed to be established in new areas due to climate change. Pathogens and their vectors are developing many resistances made compounds used to manage them. The rising incidence of multidrug resistant strains of bacteria face challenges for treating recent emerging bacterial infections with less sensitivity for antibiotics [24]. In present research, the two medicinal plants like $H$. grifithii and $C$. leiocalycinus were investigated for their antimicrobial and antifungal activities so that their therapeutic natures are disclosed to the researchers.

$H$. griffithii belongs to the family of Chenopodiaceae, familiar with name of Cat tail Family. It covers 100 genera and 1200 species [22]. The class of Haloxylon covers 13 species growing in dry places of the North-African and Arabian deserts and 
South-West Asia. The species of the genus Haloxylon are shrubbery [23]. Five species of this class are found in Pakistan [24].

Consequently, C. leiocalycinus belongs to the family of Convolvulaceae. However, Convolvulus, a genus, comprising of 200250 species of flowering plants. $C$. leiocalycinus is found in Balochistan on stony slopes at the height of $1500 \mathrm{~m}$, also found in the hilly areas of Hanna Lake, Ziarat, Brewery close to Quetta city.

\section{Materials and methods}

\section{Plant materials and sample collection}

From Hanna valley, situated in the north of Quetta and Spini road plants part of $C$. leiocalycinus and $H$. griffithii specimens were collected on May 9, 2017. The specimens were recognized by "Prof. Dr. Rasool Bakhsh Tareen", Taxonomist, University of Balochistan. Both plants were dirty with dust and thus cleaned by tap water, to save them from bacterial and fungal attack and they were air dried for half month. To maintain their metabolites, they were protected from sun rays. They were subjected to determine antifungal and antibacterial activities as long as they were dried.

\section{Instruments and reagents}

Grinder, rotary evaporator, separating funnel, beakers, round bottom flask, conical flasks, petri dishes, auto clave, laminar flow cabinet, cotton swab, wire loop, burner or spirit lamp, aluminum foil, electronic balance, refrigerator, Cork borer, tweezers, ethanol, methanol, n-hexane, ethyl acetate, chloroform, MHA (Mueller Hinton Agar) and distilled water were utilized in present research.

\section{Extracting solvent}

Solvent extraction is a method in which plants are dissolved in specific solvent to extract vital medicinal ingredients from plants. The roots, leaves and stems of the $C$. leiocalycinus and $H$. griffithii were air dried and grounded to fine powder. Separated the thick part from the powder ones and was poured to grinder for grinding. The fine powder of $5 \mathrm{~kg}$ soaked in $15 \mathrm{~L}$ of methanol for a week with shaking and infrequent stirring. To filter the mixture, the filter paper (Whatman No.1) was set. At least 3 times the extraction was done until no color changed noticed. The filtrate was evaporated on rotary evaporator. The pressure was reduced at $35^{\circ} \mathrm{C}$ to obtain a partly dehydrated crude methanolic extract (CME). Weighed a china dish and then the methanolic crude extract was poured into it. The crude was allowed for evaporation in cold, arid and dark place. The residue weighted $300 \mathrm{~g}$ after the evaporation of the residue. This CME was used for investigation of antifungal and antibacterial activities of $C$. leiocalycinus and $H$. griffithii.

\section{CME fractionation}

A process of classification of analysis wherein the dissolved compounds of CME are kept aside into various parts based on their translation \& polarities. For this, the best choice is the solvent extraction wherein the compounds are fractioned in to two parts not forming similar mixture based on their dissolvability. Usually in CME classification of analysis, the solvent selected are water $\left(\mathrm{H}_{2} \mathrm{O}\right)$, chloroform $\left(\mathrm{CHCl}_{3}\right)$, n-hexane $\left(\mathrm{C}_{6} \mathrm{H}_{14}\right)$ and ethyl acetate $\left(\mathrm{C}_{4} \mathrm{H}_{8} \mathrm{O}_{2}\right)$ relating to reduction in their polarity. The dissolved material utilized were of analytical grade. In the initial stage of segregation, the compound was segregated into non-polar, moderate polar and extremely polar. Thus, for classification of analysis, $60 \mathrm{~g}$ of CME is grinded into powder than mixed to distilled water of $200 \mathrm{~mL}$ and poured into separating funnel. Then poured $400 \mathrm{~mL}$ of $\mathrm{n}$-hexane into funnel, closed with lid and shook for 15-20 minutes. To release the pressure during shaking course, the separating pipe was released occasionally. Kept the separating funnel for fifteen minutes to segregate the two layers after shaking. Collected n-hexane layer in flask. The process was done again 3 times $(3 \times 400 \mathrm{~mL})$ to ensure no another compound going into layer of $n$-hexane to obtain the crude fraction of n-hexane. Using vacuum rotary evaporator (RV06-ML, IKA WERKE, 
GERMANY), the n-hexane was evaporated at $100 \mathrm{rpm}$ and below $15^{\circ} \mathrm{C}$ temperature. Weighed the crude and kept in freezer at $20^{\circ} \mathrm{C}$ in a labeled flask.

From earlier step, water fraction taken in separating funnel and chloroform (400mL) was used into the funnel. For 15-20 minutes the two solvent were mixed, occasionally released the separating funnel during this mixing. After the process, the funnel was kept still for 10 to 15 minutes so that two layers are entirely formed. In a separate flask, the chloroform layer was collected and two more times repeated the same step to complete extraction of solvent so that no more compounds get into water solution of chloroform layer. To get the chloroform fraction $(3 \times 400 \mathrm{~mL})$ a total of $1200 \mathrm{~mL}$ of chloroform was used. At $100 \mathrm{rpm}$ and below $25^{\circ} \mathrm{C}$ temperature, the fraction of chloroform was evaporated on vacuum rotary evaporator. The crude fraction of chloroform was weighed and kept in freezer at $-20^{\circ} \mathrm{C}$ in a labeled flask.

With water fraction, the analytical method proceeds by mixing it with ethyl acetate. First of all, in separating funnel $400 \mathrm{~mL}$ of ethyl acetate was added to water layer and were mixed for 20 to 25 minutes. Occasionally released the separating funnel to release inside pressure of funnel during shaking. For about 15 minutes, the funnel was kept still so the two immiscible layers could be segregated. The layer of ethyl acetate was placed in different flask. To clear up the ethyl acetate layer the method was repeated 3 times with ethyl acetate $(3 \times 400 \mathrm{~mL})$. In vacuum rotary evaporator, adjusting $100 \mathrm{rpm}$ and $35^{\circ} \mathrm{C}$ temperature, ethyl acetate was evaporated. The extracted crude obtained have ethyl acetate which was weighed and kept in freezer at $-20^{\circ} \mathrm{C}$ in a labeled flask.

Using $400 \mathrm{~mL}$ of n-butanol, the water layer was further analyzed in the separating funnel. These two solvents were mixed and dissolved for 15 to 20 minutes. Pressure has to be released occasionally during mixing. Almost, 30 minutes were given to separating funnel in order to separate the layers. Collected n-butanol fraction in different flask and repeated the method twice more $(2 \times 400 \mathrm{~mL})$. To condense the $\mathrm{n}$ butanol, it was evaporated at $100 \mathrm{rpm}$ and $50^{\circ}$ Ctemperature so that no further compound gets from water in n-butanol. After this, the extracted crude of n-butanol was weighed and kept in freezer at $-20^{\circ} \mathrm{C}$ in a labeled flask.

Lastly, the water was evaporated at $60^{\circ} \mathrm{C}$ at about $100 \mathrm{rpm}$ by using rotary evaporator to get aqueous fraction. Later, the crude residue of water was weighed, gathered in a tagged bottle and kept in freezer at $-20^{\circ} \mathrm{C}$.

\section{Antibacterial activity}

To find the biological activities, the methanolic extracts of the particular plants were exposed to antibacterial activity. The mechanism used to investigate antibacterial activity against selected microorganisms was agar well method.

\section{Bacterial strains}

Determining the antibacterial activity of both plant extracts, four bacterial strains were used in which three were gram negative like Pseudomonas aeruginosa $(P$. aeruginosa), Escherichia coli (E. coli), Klebsiella pneumoniae ( $K$. pneumoniae) and one was gram positive namely Staphylococcus aureus (S. aureus).

\section{Preparation of bacterial culture}

Cultures of certain bacteria were formulated in nutrient broth medium at 120 rpm for twenty-four hours at $37^{\circ} \mathrm{C}$ incubated in a shaker. These cultures were kept with temperature of $5^{\circ} \mathrm{C}$ in refrigerator after the bacterial strains were developed [25].

\section{Evaluation of antibacterial activity Agar well diffusion method Principle}

Plant extracts containing antimicrobials are spread out into the medium and merge in a plate freshly seeded with test organisms. The resulting inhibition zones will be evenly circular as there will be a confluent lawn of growth. The diameter of inhibition zones was measured in millimeters (mm). 


\section{Reagents}

Mueller Hinton agar medium (1L)

In this, $33 \mathrm{~g}$ of Mueller Hinton agar medium was dissolved in $1000 \mathrm{ml}$ of distilled water. The dissolved medium was autoclaved at $121^{\circ} \mathrm{C}$ for 15 minutes. The autoclaved medium was well mixed and poured into petri plates while still molten.

\section{Procedure}

The agar well diffusion assay was utilized to assess the antibacterial activity of both plant extracts with few alterations [26]. To prepare agar well medium, the melted Mueller Hinton agar was poured in petri dishes and allowed to consolidate. After consolidation, $6 \mathrm{~mm}$ width holes were made into agar and $10 \mu \mathrm{l}$ of the four fractions (water, ethyl acetate, chloroform and nhexane extracts) of plant extracts were added.

To prepare $100 \mathrm{mg} / \mathrm{ml}$ base of crude plant extracts for both plants, $100 \mathrm{mg}$ of plant extracts were dissolved in $1 \mathrm{ml}$ of DMSO. Furthermore, stock extract of $0.01 \mathrm{ml}$ of certain herbs was poured into each hole on the seeded medium and kept standing for an hour for appropriate diffusion. The dishes were incubated for twenty-four hours at $37^{\circ} \mathrm{C}$ and the resulting inhibition zones were determined.

\section{Antifungal activity}

To find the biological activities, the crude materials of particular plants were exposed to antifungal activity. The mechanism used to investigate antifungal activity against selected microorganism was agar well method.

\section{Fungal strain}

In the identification of antifungal activity of certain plant extracts, PBF-1 was used.

\section{Preparation of fungal culture}

Fungus was developed in Sabouraud broth for 72 hours at $28^{\circ} \mathrm{C}$. The growth of fungus can be observed by cloudiness in the broth medium. For further analysis, the fungus culture was stored in the refrigerator at 3$6^{\circ} \mathrm{C}$.

\section{Evaluation of antifungal activity Agar well diffusion method}

For the determination of fungicidal influence of plant extracts, the inhibition of mycelial growth of the fungus is used and is noticed as strong inhibition (there is no progress of the fungus), incomplete inhibition (where fungus has less growth than the normal) and no inhibition (full growth of the fungus).

Reagent (Potato Dextrose Agar Medium) To prepare potato infusion, $200 \mathrm{~g}$ peeled and sliced potatoes were boiled in 1liter distilled water for 30 minutes. Decanting through filter paper. Add 10 grams dextrose and 10 grams agar powder and pasteurized the medium by autoclaving at $121^{\circ} \mathrm{C}$ for 15 minutes.

\section{Procedure}

Nearly 20ml PDA solution and $2 \mathrm{ml}$ of fractions (water, ethyl acetate, chloroform and n-hexane) of plant extracts were combined well and the mixture was poured into pre-sterilized petri plates under Laminar air flow. The centers of petri plates were used for fungal strain. Later, the plates were incubated at $25^{\circ} \mathrm{C}$ for 48 hours. After incubation, the results were documented as strong inhibition (if test fungus shows no progress), incomplete inhibition (if test fungus has less growth than the normal) and no inhibition (if full growth of the test fungus). For reference, control plate without plant extract was also preserved.

\section{Results and discussion}

According to latest study, the antifungal and antibacterial activities of $C$. leiocalycinus and $H$. griffithii were recorded against different strains of bacteria including $S$. aureus, K. pneumonia, $P$. aeruginosa, E. coli and fungal strain like PBF-1. These plant extracts indicated variable activities.

\section{Antibacterial activity}

The in vitro antibacterial activity of different fractions (water, chloroform, ethyl acetate and n-hexane) of $C$. leiocalycinus and $H$. griffithii was assessed by Agar well assay against four pathogenic bacteria. The bacteria involved both gram negative and 
gram positive. On screening basis, it showed that all the four fractions of $H$. griffithii and $C$. leiocalycinus showed evident antibacterial activities against all the test pathogenic bacteria indicating different zones of inhibition (Table $1 \& 2$ ). The fractions of $C$. leiocalycinus was significantly active against all bacterial strains. Aqueous phased is played highest activity against $K$. pneumoniae with zone of inhibition $10 \mathrm{~mm}$, moderate activity against $P$. aeruginosa with zone of inhibition $9 \mathrm{~mm}$ and least activity against $E$. coli and $S$. aureus with zones of inhibition $6 \mathrm{~mm}$ and $7 \mathrm{~mm}$ respectively. Consequently, chloroform fraction demonstrated highest activity against $E$. coli with zone of inhibition $13 \mathrm{~mm}$, moderate activity against
$K$. pneumoniae with zone of inhibition $9 \mathrm{~mm}$ and least activity against $P$. aeruginosa and $S$. aureus with zones of inhibition $8 \mathrm{~mm}$ and $7 \mathrm{~mm}$ respectively. In addition, n-hexane phase demonstrated strong activity against $S$. aureus with zone of inhibition $7 \mathrm{~mm}$, moderate activity against $P$. aeruginosa and $E$. coli with zones of inhibition $5 \mathrm{~mm}$ and $6 \mathrm{~mm}$ and smallest activity against $K$. pneumoniae with the inhibition zone $3 \mathrm{~mm}$. Ethyl acetate phase exhibited strong activity against $K$. pneumoniae and $P$. aeruginosa with zones of inhibition $8 \mathrm{~mm}$ for both, moderate activity against $S$. aureus with zone of inhibition $6 \mathrm{~mm}$ and smallest activity against $E$. coli with zone of inhibition $5 \mathrm{~mm}$.

Table 1. Zones of inhibition in millimeter of $C$. leiocalycinus against different bacterial strains

\begin{tabular}{|c|c|c|c|c|}
\hline Fractions & S. aureus & K. pneumoniae & E. coli & P. aeruginosa \\
\hline Water & 7 & 10 & 6 & 9 \\
\hline Chloroform & 7 & 9 & 13 & 8 \\
\hline n-hexane & 7 & 3 & 6 & 5 \\
\hline Ethyl acetate & 6 & 8 & 5 & 8 \\
\hline
\end{tabular}

The fractions of $H$. griffithii extracts exhibited activity to different extent against different bacterial strains. Aqueous fraction exhibited highest activity against $P$. aeruginosa and E. coli with zones of inhibition $10 \mathrm{~mm}$ and $11 \mathrm{~mm}$, moderate activity against $S$. aureus with zone of inhibition $8 \mathrm{~mm}$ and smallest activity was showed against $K$. pneumoniae with small inhibition zone $6 \mathrm{~mm}$. Furthermore, chloroform portion showed good activity against $K$. pneumoniae with zone of inhibition $10 \mathrm{~mm}$, moderate activity against $S$. aureus and $E$. coli with zones of inhibition $8 \mathrm{~mm}$ and least activity was showed against $P$. aeruginosa with small zone of inhibition $6 \mathrm{~mm}$. Additionally, nhexane part demonstrated good activity against $S$. aureus with zone of inhibition $9 \mathrm{~mm}$, least activity for $E$. coli with small zone of inhibition $4 \mathrm{~mm}$ and did not show any activity against $K$. pneumoniae and $P$. aeruginosa. Consequently, ethyl acetate section showed good activity against $E$. coli with zone of inhibition $9 \mathrm{~mm}$, least activity against $K$. pneumoniae and $P$. aeruginosa with zones of inhibition $7 \mathrm{~mm}$. Whereas, ethyl acetate lacks the property by showing any activity against $S$. aureus (figure 1 ).

Table 2. Zones of inhibition in millimeter of $H$. griffithii against different bacterial strains

\begin{tabular}{|c|c|c|c|c|}
\hline Fractions & S. aureus & K. pneumoniae & E. coli & P. aeruginosa \\
\hline Water & 8 & 6 & 11 & 10 \\
\hline Chloroform & 8 & 10 & 8 & 6 \\
\hline n-hexane & 9 & N-A & 4 & N-A \\
\hline Ethyl acetate & N-A & 7 & 9 & 7 \\
\hline
\end{tabular}

No inhibition zone: N.A 

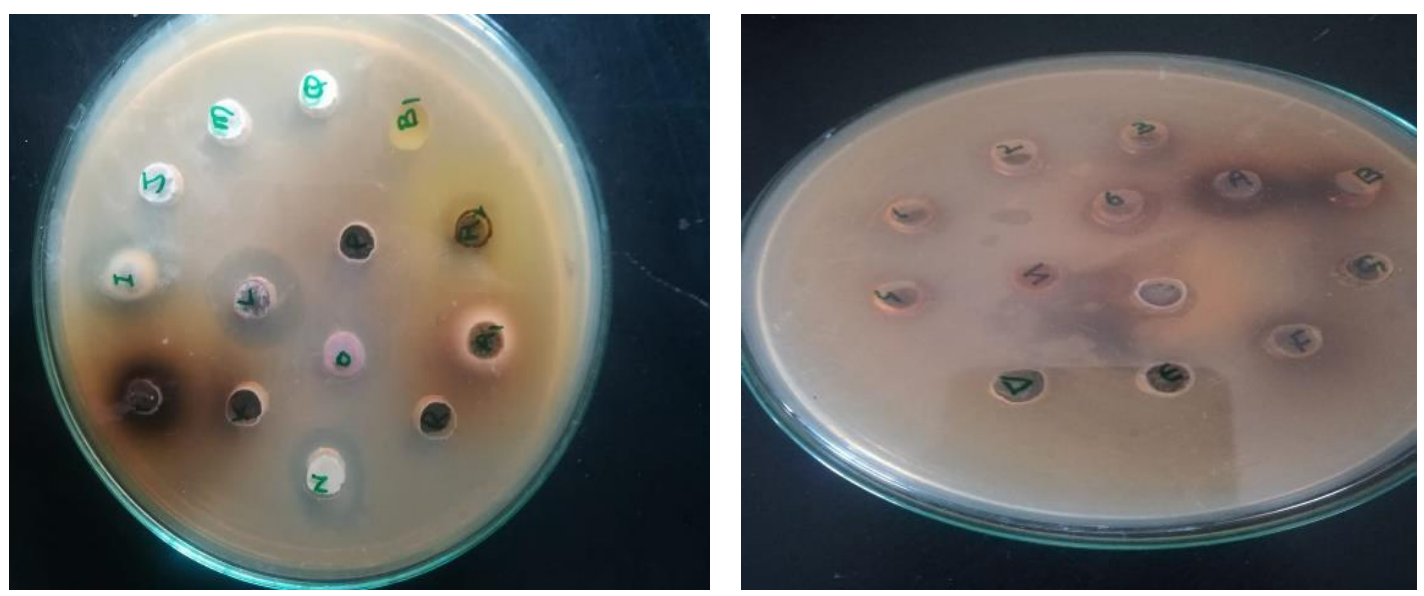

Figure 1. Inhibition zones of bacterial growth for extracts of C. leiocalycinus and $\boldsymbol{H}$. griffithii

\section{Antifungal activity}

The effect of water, chloroform, ethyl acetate and n-hexane fractions of $C$. leiocalycinus and $H$. griffithii were investigated for in vitro antifungal activity against selected fungus by Agar well assay. The test fungus employed was PBF-1.

The fractions of $C$. leiocalycinus exhibited mild antifungal activity. Aqueous fraction showed partial inhibition (test fungus has less growth) while, ethyl acetate showed strong inhibition (no progress of test fungus) (figure 2). However, chloroform and n-hexane demonstrated no inhibition (full growth of test fungus).

Considering the case of $H$. griffithii, all its fractions showed no inhibition (full growth of the test fungus) against PBF-1 except aqueous fraction which showed partial inhibition (test fungus has less growth than the normal).

In this study, the obtained results showed that the selected plants were utilized to investigate their antibacterial and antifungal activity. We noticed that the fractions of $C$. leiocalycinus exhibited considerable antibacterial and mild antifungal activities against all tested bacterial and fungal strains. Chloroform fraction of C. leiocalycinus showed good antibacterial activity while other fractions of $H$. griffithii and C. leiocalycinus showed mild antibacterial activity. Ethyl acetate fraction of $C$. leiocalycinus showed strong inhibition (no progress of test fungus). Overall antifungal activity of $H$. griffithii and $C$. leiocalycinus was not significant (table 3). The achieved results indicate that the plant extracts inhibited the growth of different microorganisms. Therefore, it showed that the plant extracts contain substances which prevent the growth of different microorganisms. At different concentrations, various researches have proved that the plant extracts prevent the development of different microorganisms [27]. Antibacterial activity of the plant extracts is considered due to the occurrence of flavonoids, tannins and alkaloids [28]. Some researchers also noticed that the presence of these different secondary metabolites in the plant extracts are responsible for antimicrobial effect [27]. Plant extracts are traditionally utilized to heal the wounds and used as ear drop in the treatment of earache and ear boils. They are also utilized to control dysentery and diarrhea [29]. 
Table 3. Antifungal activity of $\boldsymbol{H}$. griffithii and $\boldsymbol{C}$. leiocalycinus

\begin{tabular}{|c|c|c|}
\hline Plant samples & Fractions & PBF-1 \\
\hline \multirow{4}{*}{ C. leiocalycinus } & Water & + \\
\cline { 2 - 3 } & Chloroform & - \\
\cline { 2 - 3 } & n-hexane & ++ \\
\cline { 2 - 3 } & Ethyl acetate & - \\
\hline \multirow{4}{*}{ H. griffithii } & Water & - \\
\cline { 2 - 3 } & Chloroform & + \\
\cline { 2 - 3 } & n-hexane & - \\
\cline { 2 - 3 } & Ethyl acetate & \\
\cline { 2 - 3 }
\end{tabular}

$\begin{array}{lc}\text { No Inhibition } & (-) \\ \text { Mild Inhibition } & (+) \\ \text { Strong Inhibition } & (++)\end{array}$
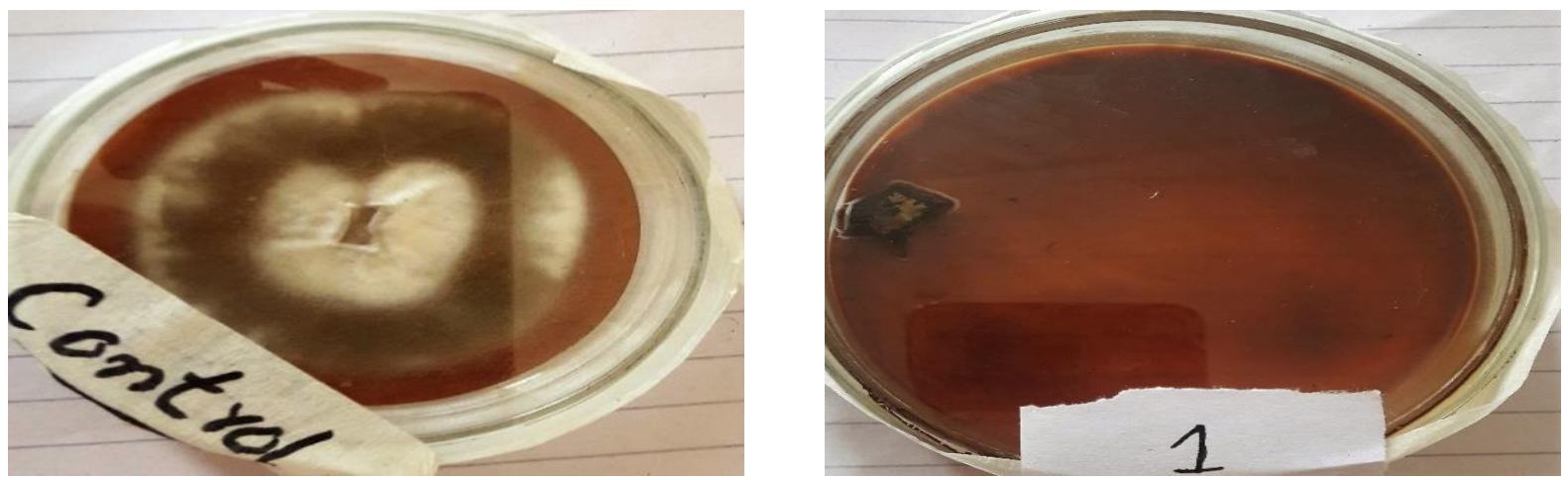

Figure 2. Antifungal activity of ethyl acetate fraction of $C$. leiocalycinus

\section{Conclusion}

The main purpose of this study is to identify the existence of antibacterial and antifungal activities in the preferred native medicinal plants of Balochistan like C. Leiocalycinus and $H$. griffithii in the province of Balochistan. In this examination, the antibacterial and antifungal activities of both the specific plants (C. leiocalycinus \& $H$. griffithii) were investigated. As a result, they exhibited substantial antibacterial and mild antifungal activities. This indicated the significance of $C$. leiocalycinus and $H$. griffithii in the treatment of different diseases. The result against different microorganisms showed the curative capacity of $C$. leiocalycinus and $H$. griffithii. It can be concluded that the extracts of $C$. leiocalycinus and $H$. griffithii can represent a fundamental part in the field of medicines. Apart from this, it can also be examined as herbal sources in pharmaceutics and can be used in food industry.

\section{Authors' contributions}

Conceived and designed the experiments: A Mengal, Samiullah \& A Baqi, Performed the experiments: A Mengal \& A Baqi, Analyzed the data: Samiullah, N Khan \& A Rehman,
Contributed materials/ analysis/ tools: Samiullah \& N Khan, Wrote the paper: A Mengal, A Baqi \& Samiullah.

\section{References}

1. Zampini IC, Cuello S \& Alberto MR (2009). Antimicrobial activity of selected plant species from the Argentine puna against sensitive and multiresistant bacteria. $J$ of Ethnopharmacol 124: 499505.

2. Okemo PO, Bais HP \& Vivanco JM (2003). In vitro activities of Maesalanceolata extracts against fungal plant pathogens. Fitoterapia 74: 312-316.

3. Bouamama H, Noel T \& Villard J (2006). Antimicrobial activities of the leaf extract of two Moroccan Cistus L species. $J$ of Ethnopharmacol 104: 104-107.

4. Hashim H, Kamali EL \& Mohammed Y (2010). Antibacterial activity and phytochemical screening of ethanolic extracts obtained from selected Sudanese medicinal plants. Curr Res J of Biological Sci 2(2): 143-146.

5. Uniyal SK, Singh KN, Jamwal P \& Lal B (2006). Traditional use of medicinal plants among the tribal communities of Chhota 
Bhangal, Western Himalayas. $J$ of Ethnobiol and Ethnomedicines 2: 1-14.

6. Kumar PA, Rajkumar \& Kanimozhi M (2010). Phytochemical screening and antimicrobial activity from five Indian medicinal plants against human pathogens. Middle-East J of Scientific Res 5(6): 477482.

7. Lai PK \& Roy J (2004). Antimicrobial and chemo preventive properties of herbs and spices. Curr Med Chem 11: 1451-1460.

8. Erdogrul OT (2002). Antibacterial activities of some plant extracts used in folk medicine. Pharmaceutical Biol 40(4): 269-273.

9. Gardam MA (2000). Is methicillinresistant Staphylococcus aureus an emerging community pathogen? A review of the literature. Can J Infect Dis 11: 202211.

10. Lepape A \& Monnet DL (2009). Experience of European intensive care physicians with infections due to antibiotic-resistant bacteria. Euro Surveill 14(45):19393.

11. Alviano DS \& Alviano CS (2009). Plant extracts: search for new alternatives to treat microbial diseases. Curr Pharm Biotechnol 10: 106-121.

12. Hemaiswarya $S$, Kruthiventi AK \& Doble M (2008). Synergism between natural products and antibiotics against infectious diseases. Phytomedicine 15:639-652.

13. Mahady GB (2005). Medicinal plants for the prevention and treatment of bacterial infections. Curr Pharm Des 11: 24052427.

14. Iwu MW, Duncan AR \& Okunji CO (1999). New antimicrobials of Plant Origin. In: J. Janick 457-462.

15. Livemore DM (2003). Overstretching the mutant prevention concentration. $J$. Antimicrob Chemother 52: 732.

16. Walsh FM \& Amyes (2004). Microbiology and drug resistance mechanisms of fully resistant pathogens. Curr Opi Micro 7: 439-444.

17. Solomon S, Horan T, Andrus M, Edwards J, Fridkin S, Koganti J, Peavy G \& Tolson J (2003). National Nosocomial Infections Surveillance (NNIS) system report, data summary from January 1992 through June 2003, issued August 2003. Am J Infect Control 31: 481-498.
18. Alder JD (2005). Daptomycin, a new drug class for the treatment of Gram-positive infections. Drugs Today 41(2): 81.

19. Newman DJ, Cragg GM \& Snader KM (2003). Natural products as sources of new drugs over the period.

20. Renisheya JJ, Malar T, Johnson M, Mary UM \& Arthy A (2011). Antibacterial activities of ethanolic extracts of selected medicinal plants against human pathogens. Asian Pac J Trop Biomed, pp S76-S78.

21. Bushra I, Fozia, Abdul W, Ali R, Hussain U, Iqbal H, Almas M \& Ahmad A (2012). Antimicrobial activity of Malva neglecta and Nasturtium microphyllum. Int J Res Ayurveda Pharm 3: 808-810.

22. Bibi Y, Nisa S, Chaudhary F \& Zia M (2011). Antibacterial activity of some selected medicinal plants of Pakistan. BMC Complem Altern Med 11: 892-897.

23. Munir S, Jamal Q, Shirwani S, Sualeh M, Jabeen U, Malik MS \& Hussain M (2013). Antibacterial activity of two medicinal plants, Withania somnifera and Cuccuma longa. Eur Acad Res 1: 1335-1345.

24. Sieradzki K, Roberts RB, Haber SW \& Tomasz A (1999). The development of vancomycin resistance in a patient with methicillin-resistant Staphylococcus aureus infection. New England $J$ of Medicine 340: 517-523

25. Dhale DA \& Markandeya SK (2011). Antimicrobial and phytochemical screening of Plumbago zeylanica Linn. (Plumbaginaceae) leaf. $J$ of Experimental Sci 2(3).

26. Irshad $S$, Mahmood $M$ \& Perveen $F$ (2012). In vitro antibacterial activities of three medicinal plants using agar well diffusion method. Res $J$ of Biol 2(1): 1-8.

27. Nweze EI, Okafor JI \& Njoku O (2004). Antimicrobial activities of methanolic extracts of Tremaguineensis (Schumm and Thorn) and Morinda lucida Benth used in Nigerian Herbal Medicinal Practice. $J$ of Biological Res and Biotechnolm 2(1): 3946.

28. Draughon FA (2004). Use of Botanicals as Bio preservatives in Foods. Food Technol 58(2): 20-28.

29. Igoli JO, Ogaji TA, Tor A \& Igoli NP (2005). Traditional medicine practice amongst the Igede people of Nigeria. Part II. Afr J Trad CAM 2(2):134-152. 